\title{
Research on Badminton Education Teaching Quality Evaluation System Based on Fuzzy Analytic Hierarchy Process
}

\author{
Jinli Yang ${ }^{1}$, Songshan Zhou ${ }^{2}$ Jie Ren $^{3}$ \\ ${ }^{1}$ Department of Sports Training, Hebei Institute of Physical Education, Shijiazhuang, China \\ y_ang_jinli@126.com \\ ${ }^{2}$ Wushu Department, Hebei Institute of Physical Education, Shijiazhuang, China \\ ${ }^{3}$ Department of Pubic Education, Shijiazhuang Institute of Technology, Shijiazhuang. China
}

Keywords: fuzzy analytic hierarchy process, badminton, education and teaching quality, evaluation system

\begin{abstract}
In order to evaluate the teaching quality of the badminton teachers and improve the teaching quality, in this article, the fuzzy analytic hierarchy process is used to establish badminton teaching quality evaluation system. We evaluate the teaching quality from four aspects such as teaching attitude, teaching content, teaching method and teaching effect and establish a three layer hierarchical structure. After constructing a fuzzy consistency matrix, we obtain the weights of the indicators in all layers and the combined weights of the indicators in the bottom layer. The comprehensive indicator calculated from the combined weight can reflect the teaching quality of the badminton teacher. By using the theory of fuzzy sets, the weights of the indicators can be determined so that the evaluation result can be more scientific. This system offsets the shortage of the badminton education teaching quality evaluation, which can improve the badminton education and its teaching quality.
\end{abstract}

\section{Introduction}

Badminton education teaching quality evaluation is the significant method to evaluate the teaching comprehensive level of the teachers and is the main approach to manage the badminton teaching scientifically. We usually combine expert evaluation, colleague peer assessment and students appraising teaching to evaluate the teaching quality of badminton teachers. The human factor can influence the evaluation result and make it different from the practical situation, which can not reflect the authenticity and justification. Even it may influence the teaching enthusiasm, which is bad to the teaching process. As a PE course, badminton curriculum is different from other theoretical ones. It is implemented on the playground. The students are of different levels. So it is difficult to determine the factors in the process of teaching evaluation. It is not realistic to quantify all the determined factors. So we will use the qualitative and quantitative methods to implement the badminton teaching quality evaluation. Some scholars use AHP to study PE teaching quality evaluation. But the traditional AHP usually uses Saaty's weight method to determine the weights of all the indicators and asks the pairwise comparison judgment matrix to have satisfactory consistency. In practice, when the exponent number is larger, the consistency of judgment matrix isn't always satisfactory. So the established education teaching evaluation system has problems. In the overall PE system teaching quality evaluation, there is no badminton teaching quality evaluation research. Different PE course has different characters, so using same evaluation indicator system can not reflect the teaching quality of the teachers. In order to offset the shortage of the research of badminton teaching quality evaluation and the disadvantage of the traditional evaluation method, we use fuzzy analytic hierarchy process to evaluate the badminton education teaching quality, which can provide reference for badminton education teaching quality evaluation. 


\section{Summary of Fuzzy Analytic Hierarchy Process}

A. Fundamental Principle of Fuzzy Analytic Hierarchy Process

Fuzzy analytic hierarchy process can offset the difficulties and unscientific problems caused when AHP assesses the consistency of judgment matrix. The principle of Fuzzy AHP is almost the same with that of AHP. Fuzzy AHP uses qualitative analysis and quantitative analysis at the same time, which can systemize, qualify and model the complicated problems. This means that we should resolve the complicated problem into several elements and then the elements should be further resolved into more specific, detailed and quantified small elements (indicators). According to the significance, the weights of the elements should be determined. Then we use the weights to connect the layers to establish a statistical model with multiple targets and multiple layers. Fuzzy AHP and traditional AHP have two differences. One is that AHP establishes judgment matrix by pairwise comparison of all the indicators and test the consistency of the matrix, but Fuzzy AHP establishes fuzzy consistency matrix by pairwise comparison of all the indicators without the test of the consistency. The second difference is the calculation methods of indicator weights.

B. The Basic Steps of Fuzzy AHP

The basic steps of Fuzzy AHP is similar to traditional AHP, which is shown as below,

1) Establish a multi-layer hierarchical structure, forming a target tree diagram.

Fuzzy AHP includes three layers which are top layer, middle layer and bottom layer. Please see Fig. 1. The top layer is the target layer which is overall target of AHP. The middle layer is also called constrained layer which includes some factors influencing the overall target. The bottom layer is called measurement layer which includes the final measurement. The measurement can solve the problem and can be quantified.

2) Construct Fuzzy Consistency Matrix.

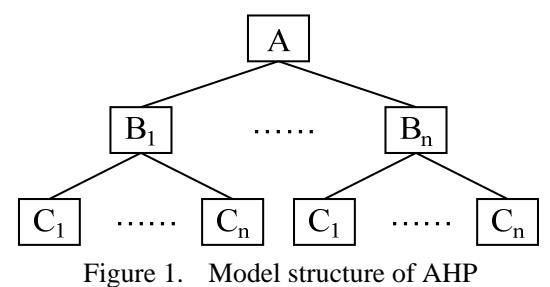

We use R to represent fuzzy consistency judgment matrix. First we choose one indicator in the upper layer and determine the related indicator in the lower layer. Compare the relative significances of the indicators. Suppose the indicator $C$ in the upper layer can be explained by indicator $a_{1}, a_{2}, \cdots, a_{n}$ in the lower layer. Then we can construct a fuzzy consistency judgment matrix which is shown in table 1.

TABLE I.
\begin{tabular}{|c|c|c|c|c|}
\hline C & $a_{1}$ & $a_{2}$ & $\cdots$ & $a_{n}$ \\
\hline$a_{1}$ & $r_{11}$ & $r_{12}$ & $\cdots$ & $r_{1 n}$ \\
\hline$a_{2}$ & $r_{21}$ & $r_{22}$ & $\cdots$ & $r_{2 n}$ \\
\hline$\cdots$ & $\cdots$ & $\cdots$ & $\cdots$ & $\cdots$ \\
\hline$a_{n}$ & $r_{n 1}$ & $r_{n 2}$ & $\cdots$ & $r_{n n}$ \\
\hline
\end{tabular}

$r_{i j}(i=1,2, \cdots, n ; j=1,2, \cdots, n)$ represents the proportion of degree of significance between $a_{i}$ and $a_{j}$ which are the $\mathrm{i}^{\text {th }}$ indicator and $\mathrm{j}^{\text {th }}$ indicator of $\mathrm{C}$ in the upper layer. In order to quantify the degree of importance, we will use the following grading standard shown in Table 2. 
TABLE II. THE GRADING STANDARD IN EACH LAYER OF FUZZY AHP

\begin{tabular}{|l|l|l|}
\hline \multicolumn{1}{|c|}{ The importance scale $r_{i j}$} & Relative degree of importance & \\
\hline 0.5 & Equally important & The two indicators are equally important after comparison. \\
\hline 0.6 & Somewhat important & $\begin{array}{l}\text { One indicator is somewhat important than the other after } \\
\text { comparison. }\end{array}$ \\
\hline 0.7 & Obviously important & $\begin{array}{l}\text { One indicator is obviously important than the other after } \\
\text { comparison. }\end{array}$ \\
\hline 0.8 & Indeed important & One indicator is indeed important than the other after comparison. \\
\hline 0.9 & Absolutely important & $\begin{array}{l}\text { One indicator is absolutely important than the other after } \\
\text { comparison. }\end{array}$ \\
\hline $0.1,0.2,0.3,0.4$ & Converse comparison & $\begin{array}{l}\text { If the importance ratio between } a_{i} \text { and } a_{j} \text { is } r_{i j}, \text { the importance } \\
\text { ratio between } a_{j} \text { and } a_{i} \text { is } r_{j i}=1-r_{i j} \cdot\end{array}$ \\
\hline
\end{tabular}

According to the scoring method in Table 2, after the pairwise comparison of evaluation indicators $a_{1}, a_{2}, \cdots, a_{n}$ of indicator $\mathrm{C}$, we can get fuzzy judgment matrix shown below,

This matrix has three properties which are

$$
R=\left[\begin{array}{cccc}
r_{11} & \mathrm{r}_{12} & \cdots & \mathrm{r}_{1 \mathrm{n}} \\
r_{21} & \mathrm{r}_{22} & \cdots & \mathrm{r}_{2 \mathrm{n}} \\
\cdots & \cdots & \cdots & \cdots \\
\mathrm{r}_{\mathrm{n} 1} & \mathrm{r}_{\mathrm{n} 2} & \cdots & \mathrm{r}_{\mathrm{nn}}
\end{array}\right]
$$

$$
\begin{aligned}
& \text { (1) } \mathrm{r}_{\mathrm{ii}}=0.5, i=1,2, \cdots, n ; \\
& \text { (2) } \mathrm{r}_{\mathrm{ij}}=1-r_{j i}, i, j=1,2, \cdots, n ; \\
& \text { (3) } \mathrm{r}_{\mathrm{ij}}=r_{i k}-r_{j k}, i, j, k=1,2, \cdots, n .
\end{aligned}
$$

3 ) Calculate the weights of all the indicators

Suppose the weight set of indicators $a_{1}, a_{2}, \cdots, a_{n}$ is $W=\left(\omega_{1}, \omega_{2}, \cdots, \omega_{n}\right)$, then

$$
r_{i j}=0.5+a\left(\omega_{i}-\omega_{j}\right), \quad i, j=1,2, \cdots, n
$$

In the formula, $0<a \leq 0.5, a$ is the evaluation which the evaluator imposes on the evaluation objects.

When $\mathrm{R}$ is not consistent, the above formula is not strictly true and we can use the least squares principle to obtain weight vector $W=\left(\omega_{1}, \omega_{2}, \cdots, \omega_{n}\right)$, which shown in below,

$$
\left\{\begin{array}{l}
\min z=\sum_{i=1}^{n} \sum_{j=1}^{n}\left[0.5+a\left(\omega_{i}-\omega_{j}\right)-r_{i j}\right]^{2} \\
\text { s.t. } \sum_{i=1}^{n} \omega_{i}=1, \omega_{i} \geq 0,(1 \leq i \leq n)
\end{array}\right.
$$

According to Lagrange's theorem, the above formula and the below one is equal in value.

$$
\min L(\omega, \lambda)=\sum_{i=1}^{n} \sum_{j=1}^{n}\left[0.5+a\left(\omega_{i}-\omega_{j}\right)-r_{i j}\right]^{2}+2 \lambda\left(\sum_{i=1}^{n} \omega_{i}-1\right)
$$

And $\lambda$ in the formula is the Lagrange multiplier.

Calculate the partial derivative of $\min L(\omega, \lambda)$ with $\min L(\omega, \lambda)$ and suppose it equals to zero. Then we can get the following equations.

$$
\begin{gathered}
a \sum_{j=1}^{n}\left[0.5+a\left(\omega_{i}-\omega_{j}\right)-r_{i j}\right]-a \sum_{k=1}^{n}\left[0.5+a\left(\omega_{k}-\omega_{i}-r_{k i}\right]+\lambda=0\right. \\
(i=1,2, \cdots, n)
\end{gathered}
$$

The equations are equivalent to the following equations

$$
\begin{aligned}
& \sum_{j=1}^{n}\left[2 a^{2}\left(\omega_{i}-\omega_{j}\right)+a\left(r_{j i}-r_{i j}\right)\right.+\lambda=0 \\
&(i=1,2, \cdots, n)
\end{aligned}
$$

The number of unknown number is $\mathrm{n}+1$ which is $\omega_{1}, \omega_{2}, \cdots \omega_{n}, \lambda$. The number of equations is $\mathrm{n}+1$. 


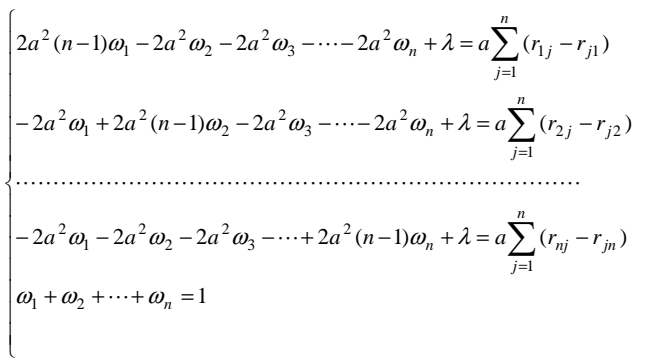

After solving the equations, we can get the weights of the evaluation indicators.

4) Calculate the combined weight $C_{i}$ of the indicators in the bottom layer by using weighting method.

$C_{i}=$ Indicator Weights of Layer B * Indicator Weights of Layer C

5) Calculating Comprehensive Index GI

If there are low priority indicators and high priority indicators in the selected evaluation indicators, we should implement convergence process. The method is as follows. High priority indicator $\mathrm{Pi}=$ actual value/desired value; low priority indicator $\mathrm{Pi}=$ desired value $/$ actual value. After the convergence process, we calculate the comprehensive index ${ }_{G I}=\sum_{j=1}^{m} C_{i} P_{i}$.

\section{Establishment of Badminton Education Teaching Quality Evaluation System}

The Selection of Evaluation Indicators

The badminton education teaching quality evaluation system is comparatively complicated and there are a lot of influential factors. So the establishment of badminton education teaching quality evaluation system is a big project. The selection of the evaluation indicators will influence the evaluation system. In order to select the indicators of badminton education teaching quality evaluation system more comprehensively, systematically and scientifically and improve the accuracy of the evaluation, we should make the indicators more scientifically and practically. In the process of selection of the indicators, we should regard target guidance quality, scientificity, globality, objectiveness and practicality as the basic principles. Combining with the basic theory and the teaching practice, from the aspects of teaching attitude, teaching content, teaching method and teaching effects, we preliminarily select the factors which influence badminton education teaching quality evaluation system as the indicators. After selecting the indicators, we have consulted the professors engaging in the badminton teaching, experts engaging in teaching management and theoretical research. With their opinions, we select teaching attitude, teaching content, teaching method and teaching effect as the indicators of PE teaching evaluation system. Then each indicator is resolved into different indicators and we establish a three-layer hierarchical structure which shown in Table 3.

TABLE III. BADMINTON EDUCATION TEACHING QUALITY EVALUATION INDICATORS SYSTEM

\begin{tabular}{|c|c|c|}
\hline First Level Indicator A & Second Level Indicator B & Third Level Indicator C \\
\hline \multirow{13}{*}{ Education Teaching Quality A } & \multirow{4}{*}{ Teaching Attitude B1 } & Teaching Plan Preparation C1 \\
\hline & & Teaching Term Plan C2 \\
\hline & & To Be in Class and Finish Class on Time C3 \\
\hline & & Training After Class C4 \\
\hline & \multirow{3}{*}{ Teaching Content B2 } & Rationality of Contents C5 \\
\hline & & Cohesion of Contents C6 \\
\hline & & Utilization of Supplementary Contents C7 \\
\hline & \multirow{3}{*}{ Teaching Method B3 } & Scientificity C7 \\
\hline & & Innovation C9 \\
\hline & & Variety C10 \\
\hline & \multirow{3}{*}{ Teaching Effect B4 } & Ability Improvement of Students C11 \\
\hline & & Test Scores of Students C12 \\
\hline & & Educational Attraction C13 \\
\hline
\end{tabular}

Establishment of Fuzzy Consistency Matrix

According to the above mentioned establishment method of fuzzy consistency matrix, we establish the fuzzy consistency matrixes of each layer. 
TABLE IV. FUZZY CONSISTENCY MATRIX OF FIRST LEVEL INDICATORS

\begin{tabular}{|l|l|l|l|l|}
\hline A & B1 & B2 & B3 & B4 \\
\hline B1 & 0.5 & 0.8 & 0.7 & 0.6 \\
\hline B2 & 0.2 & 0.5 & 0.4 & 0.3 \\
\hline B3 & 0.3 & 0.6 & 0.5 & 0.4 \\
\hline B4 & 0.4 & 0.7 & 0.6 & 0.5 \\
\hline
\end{tabular}

TABLE V. FUZZY CONSISTENCY MATRIX OF SECOND LEVEL INDICATORS (TEACHING ATTITUDE)

\begin{tabular}{|l|l|l|l|l|}
\hline B1 & C1 & C2 & C3 & C4 \\
\hline C1 & 0.5 & 0.5 & 0.3 & 0.4 \\
\hline C2 & 0.5 & 0.5 & 0.3 & 0.4 \\
\hline C3 & 0.7 & 0.7 & 0.5 & 0.6 \\
\hline C4 & 0.6 & 0.6 & 0.4 & 0.5 \\
\hline
\end{tabular}

TABLE VI. FUZZY CONSISTENCY MATRIX OF SECOND LEVEL INDICATORS (TEACHING CONTENT)

\begin{tabular}{|l|l|l|l|}
\hline B2 & C5 & C6 & C7 \\
\hline C5 & 0.5 & 0.6 & 0.7 \\
\hline C6 & 0.4 & 0.5 & 0.6 \\
\hline C7 & 0.3 & 0.4 & 0.5 \\
\hline
\end{tabular}

TABLE VII. FUZZY CONSISTENCY MATRIX OF SECOND LEVEL INDICATORS (TEACHING METHOD)

\begin{tabular}{|l|l|l|l|}
\hline B3 & C8 & C9 & C10 \\
\hline C8 & 0.5 & 0.6 & 0.6 \\
\hline C9 & 0.4 & 0.5 & 0.5 \\
\hline C10 & 0.4 & 0.5 & 0.5 \\
\hline
\end{tabular}

TABLE VIII. FUZZY CONSISTENCY MATRIX OF SECOND LEVEL INDICATORS (TEACHING EFFECT)

\begin{tabular}{|l|l|l|l|}
\hline B4 & C11 & C12 & C13 \\
\hline C11 & 0.5 & 0.7 & 0.8 \\
\hline C12 & 0.3 & 0.5 & 0.6 \\
\hline C13 & 0.2 & 0.4 & 0.5 \\
\hline
\end{tabular}

Calculating the Weights of Indicators

According to formula (4), we construct equations of each fuzzy consistency matrix. Then we use Matlab software to program and get the weights of the indicators in the matrixes.

The weight vector of second level indicators in the badminton education teaching quality is $W_{1}=[0.323,0.177,0.226,0.274]^{T}$.

The weight vector of the evaluation indicator in second level indicator teaching attitude is $W_{2}=[0.213,0.213,0.311,0.262]^{T}$.

The weight vector of the evaluation indicator in second level indicator teaching content is $W_{3}=[0.4,0.333,0.267]^{T}$.

The weight vector of the evaluation indicator in second level indicator teaching method is $W_{4}=[0.35,0.3,0.35]^{T}$.

The weight vector of the evaluation indicator in second level indicator teaching effect is $W_{5}=[0.444,0.311,0.244]^{T}$.

So we can get badminton education teaching quality evaluation system which is shown in Table 9 .

\begin{tabular}{|c|c|c|c|c|c|}
\hline First Level Indicator A & $\begin{array}{l}\text { Second Level Indicator } \\
\text { B }\end{array}$ & Weight & Third Level Indicator C & Weight & $\begin{array}{l}\text { Combined } \\
\text { Weight }\end{array}$ \\
\hline \multirow{13}{*}{$\begin{array}{l}\text { Education Teaching Quality } \\
\text { A }\end{array}$} & \multirow{4}{*}{ Teaching Attitude B1 } & \multirow[t]{4}{*}{0.323} & Teaching Plan Preparation C1 & 0.213 & 0.069 \\
\hline & & & Teaching Term Plan C2 & 0.213 & 0.069 \\
\hline & & & $\begin{array}{l}\text { To Be in Class and Finish Class on Time } \\
\text { C3 }\end{array}$ & 0.311 & 0.1 \\
\hline & & & Training After Class C4 & 0.262 & 0.085 \\
\hline & \multirow{3}{*}{ Teaching Content B2 } & \multirow[t]{3}{*}{0.177} & Rationality of Contents C5 & 0.4 & 0.071 \\
\hline & & & Cohesion of Contents C6 & 0.333 & 0.059 \\
\hline & & & Utilization of Supplementary Contents C7 & 0.267 & 0.047 \\
\hline & \multirow{3}{*}{ Teaching Method B3 } & \multirow[t]{3}{*}{0.226} & Scientificity C7 & 0.35 & 0.079 \\
\hline & & & Innovation C9 & 0.3 & 0.068 \\
\hline & & & Variety C10 & 0.35 & 0.079 \\
\hline & \multirow{3}{*}{ Teaching Effect B4 } & \multirow[t]{3}{*}{0.274} & Ability Improvement of Students C11 & 0.444 & 0.122 \\
\hline & & & Test Scores of Students C12 & 0.311 & 0.085 \\
\hline & & & Educational Attraction C13 & 0.244 & 0.067 \\
\hline
\end{tabular}

According to the combined weight of indicators in the bottom layer of the evaluation system, we can calculate the comprehensive index GI of the badminton teachers. According to the values of GI, we can rank and evaluate the education teaching quality of the badminton teachers. 


\section{Conclusion}

In this research, fuzzy analytic hierarchy process is used to establish badminton education teaching quality evaluation system. This method scientifically quantifies all the evaluation indicators. We establish fuzzy consistency matrix to analyze the importance degree of the indicators and obtain a comparatively good research result. This evaluation system offsets the shortage of the badminton education teaching quality evaluation, which can improve the badminton education and its teaching quality.

\section{References}

[1] Xu Jinye, The Professional Sports Club Performance Evaluation Based on Balanced Scorecard and AHP [J], Sports and Scientific Research, 2007, (1) : 26-28.

[2] Li Fengxiang, Song Jie, Research on Fitness Environmental Evaluation System and Standards of Shandong Peninsula City Community [J], Wuhan Institute of Physical Education Journal, 2006, (5) : 40-44.

[3] Ding Suwen, Zhou Tianjing, Research on Introducing FUZZY Formula Method into PE Curriculum Teaching Quality [J], Hebei Institute of Physical Education Journal, 2003, (3) : 42-43.

[4] Cao Limin, Research on Physical Education Teaching Quality Evaluation and Indicator System [J], Hunan Institute of Science and Technology Journal (Version of Natural Science), 2003, (4) : 87-89.

[5] Wei Lilan, Qin Jianbo, The Application Research on FAHP in College Classroom Teaching Quality Evaluation [J], SMEs Management and Technology, 2012(10):192-193.

[6] Lv Yuejin, The Ranking of Fuzzy AHP Based on Fuzzy Consistency Matrix [J], Fuzzy System and Mathematics, 2002, 16(2) : 79-85.

[7] Jiang Yanping, Fan Zhiping, One New Approach to Regulate the Consistency of Fuzzy Judgment Matrix [J], Fuzzy System and Mathematics, 2002, 16(2) : 74-78.

[8] Song Guangxing, Yang Deli, Consistency Examination of Fuzzy Judgment Matrix and Consistency Improvement Method [J], Systematic Engineering, 2003, 21(1) : 110-116.

[9] Fan Zhiping, Jang Yanping, The Consistency Improvement Method of Complementary Judgment Matrix [J], Northeastern University Journal (Version of Natural Science), 2003, 24(1) : 98-101.

[10] Yao Min, Huang Yanjun, Fuzzy Decision Method Research [J], System Engineering and Practice, 1999, 19(11) : 61-64.

[11] Lin Junchang, Xu Zeshui, One New Scale Method in Fuzzy AHP [J], Operation Research and Management Science, 1998, 7(2) : 37-40.

[12] Jiang Yanping, Fan Zhiping, The Consistency Adjustment Method of Fuzzy Judgment Matrix [J], Mathematical Practice and Cognition, 2003, 33(12) : 82-87.

[13] Xu Zeshui, One Improved Building Method of Fuzzy Consistency Judgment Matrix [J], Applied Mathematics and Computational Mathematics Journal, 1996, 11(2) : 63-67.

[14] Du Dong, Further Study of AHP Based on 0.1-0.9 Calibration [J], System Engineering and Electronic Technology, 2001, 23(5) : 36-38.

[15] Wang Yanmei, Zhao Xinan, Guo Mei, One Method of Adjusting Fuzzy Judgment Matrix Consistency [J], Fuzzy System and Mathematics, 2006, 20(3) : 89-94. 